\title{
Sub-Clinical Hypothyroidism and Its Association With Increased Cardiovascular Mortality: Call for Action
}

\author{
Abdalla Hassan ${ }^{\mathrm{a}}$, Alvaro Altamirano-Ufion ${ }^{\mathrm{a}, \mathrm{c}}$, Beenish Zulfiqar ${ }^{\mathrm{a}}$, \\ Prajwal Boddu ${ }^{\mathrm{b}}$
}

\begin{abstract}
Thyroid hormones play an important role in regulating different functions regarding metabolism and performance in multiple organs. Any change in the thyroid hormones axis can lead to profound effect on the vital organ stability especially the cardiovascular system. Hypothyroidism is classified according to the clinical presentation as overt and subclinical. Currently, there exists a paucity of evidence on the beneficial effects of thyroxine hormone replacement on cardiovascular mortality outcomes in subclinical hypothyroidism. Also, the clinical relevance of measuring and treating supra-normal thyroid-stimulating hormone levels in newly diagnosed heart failure patients with preserved ejection fraction requires further study. Here we review the current evidence regarding the prognostic significance of sub-clinical hypothyroidism in patients with heart failure with preserved ejection fraction.
\end{abstract}

Keywords: Sub-clinical hypothyroidism; Heart failure with preserved ejection fraction; Cardiovascular mortality

\section{Introduction}

Thyroid hormones are responsible for regulating different functions regarding metabolism and performance in multiple organs. When the thyroid hormones axis is altered, it can lead to either hypo- or hyperthyroidism. Hypothyroidism is classified according to the clinical presentation as overt and subclinical. Subclinical hypothyroidism is defined as an increase in the levels of thyroid-stimulating hormone (TSH) with a normal level of T3 and T4 in the absence of symptoms. Overt hypothyroidism has been studied more than subclinical hypothyroidism and is well known to be associated with cardiovas-

Manuscript accepted for publication February 06, 2017

aAdvocate Illinois Masonic Medical Center, Chicago, IL, USA

${ }^{\mathrm{b}}$ Anderson M.D. Hospital, USA

${ }^{\mathrm{c} C}$ Corresponding Author: Alvaro Joaquin Altamirano-Ufion, Advocate Illinois

Masonic Medical Center, Chicago, IL, USA.

Email: alvaro.altamiranoufion@advocatehealth.com

doi: https://doi.org/10.14740/cr524w cular disease such as accelerated atherosclerosis and coronary artery disease. Both $\mathrm{T} 3$ and $\mathrm{T} 4$ seem to have beneficial effects in the cardiovascular system. T3 facilitates myocardial relaxation and decreases peripheral vascular resistance, whereas T4 replacement therapy has proven to be beneficial in improving hemodynamic effects in patients with subclinical hypothyroidism [1].

Currently, there exists a paucity of evidence on the beneficial effects of thyroxine hormone replacement on cardiovascular mortality outcomes in subclinical hypothyroidism. Also, the clinical relevance of measuring and treating supranormal TSH levels in newly diagnosed heart failure patients with preserved ejection fraction requires further study. It has been proven beyond doubt that thyroid hormone metabolism can be altered in heart disease. Conversely, thyroid hormone dysfunction can result in altered ventricular contractility/relaxation dynamics and compromised cardiac function. This fact has important clinical implications in that thyroid dysfunction represents one of the few potentially reversible causes of heart failure [2].

\section{Genetics}

T4 constitutes the major circulating fraction of thyroid hormone in the human body. T4 is transformed by iodothyronine deiodinase into T3, the biologically active form, responsible for thyroxine's effects on target end organs. T3 affects the cardiac muscle through two different mechanisms, genomic and non-genomic. Genomic effects are achieved through upregulation in the expression of genes involved in the production of structural proteins including SERCA and cardiac myosin heavy chain [3]. Low thyroid hormone levels lead to decreased levels of SERCA2 activity, which controls the contraction and relaxation cycle through an ATPase with affinity for calcium, leading to myocardial stiffness and eventually left ventricular diastolic dysfunction [4]. T3 binds to the thyroid hormone receptors in the nucleus. These nuclear receptors bind themselves to thyroid hormone responsive elements located in the promoter regions of specific genes. In the heart, these types of receptors have been identified as TR alpha1, TR alpha2, TR beta1 and TR beta2 [5]. They have different functions and can act as positive or negative regulators. For instance, the TR alphal plays an important role in regulating some physiologic functions in the heart, while TR alpha2 has an antagonistic 
physiological role in exerting negative regulatory effects on TR alpha1 [6].

Thyroid hormones are involved in the regulation of hyperpolarization-activated cyclic nucleotide gated channels and proteins, and genes encoded in specialized pacemaker cells. Also, the angiotensin receptors in the smooth muscle cells of the vessels seem to be regulated by the T3 nuclear receptor [7]. Endothelial microprticles which have been linked to endothelial injury and dysfunction have also been found in patients with subclinical hypothyroidism and ischemic heart disease and congestive heart failure [2]. It has been observed that some of the involved genes encode for specific type of proteins that participate in the contraction process of the heart muscle such as alpha and beta (as mentioned above), the sodium calcium exchanger, phospholamban and the beta adrenergic receptor MHC. Once the expression of these genes is altered, there is a cascade of events where cardiac contractility, calcium cycling and diastolic relaxation can be affected with the subsequent development of heart failure [8].

Patients with low levels of thyroid hormones seem to fall into a cycle where the low levels of thyroid hormones lead to heart failure and at the same time heart failure can downregulate the signal of the thyroid hormones in the heart with a net effect of increasing overall mortality. If we combine this phenomenon with the effects on structures other than cardiac tissue, the overall mortality becomes significantly high [9]. One well known example to mention is the association between higher levels of cholesterol in patients with hypothyroidism either overt or subclinical and as we know hyperlipidemia is the main risk factor for coronary heart disease (CHD) that ultimately can lead to heart failure but more importantly some studies suggest that in more than $90 \%$ of patients with overt hypothyroidism and even patients with subclinical hypothyroidism, we can find derangements of the lipid profile including LDL and apolipoprotein A and treatment with thyroid hormones can lead to reversal of this derangements [10].

Another example to mention is the fact that some histological changes have been reported in some animal studies wherein animals have low levels of thyroid hormones; there is an accumulation of mucopolysaccharides in the heart which can lead to impairment of the myocardium similar to the one caused by other conditions that can lead to mucopolysaccharides accumulation in humans where most of them are genetic conditions and eventually lead to heart failure. Although strong evidence of this in humans lacks, there have been case reports reporting this association [11].

One last example of this ubiquitous interaction between hypothyroidism and heart failure is related to T3 levels which have shown a direct correlation with the degree of left ventricular dysfunction and levels of NT-pro beta natriuretic peptide, meaning the lower the T3 levels but more left ventricular dysfunction and the higher the biological marker. This correlation though did not exist with levels of T4 or TSH. At the clinical level there is correlation between low levels of T3 and idiopathic dilated cardiomyopathy [12].

This conclusion leads to an important question. If hypothyroidism is associated to increased mortality in heart failure, even subclinical hypothyroidism and some studies suggest that there is a benefit on replacing thyroid hormones, at what extent should we consider replacing them?

Regarding the question of whether subclinical hypothyroidism is associated to an increase or potentiation of risk factors for heart failure, we found in a study by Rodondi et al that the following risk factors have a statistically significant association with subclinical hypothyroidism: smoking, diabetes, presence of peripheral vascular disease and high cholesterol levels. In the same study, there was a direct association with congestive heart failure, although the levels of TSH were $>7$ $\mathrm{mIU} / \mathrm{L}$ to be statistically significant and also this was studied only in hospitalized patients [13].

\section{Discussion}

Clinical signs and symptoms poorly predict thyroid status, especially in the elderly population, and the diagnosis of subclinical hypothyroidism is based purely on biochemical grounds of elevated TSH with normal free thyroxine. As the diagnosis rests on an elevated level of TSH, identifying the upper limit of reference range is critical in defining subclinical hypothyroidism. Observations from the composite of all age groups in the NHANES III study designated a TSH level of $4.5 \mathrm{mIU} / \mathrm{L}$ as upper range of normal [14]. Various studies have suggested an increase in the incidence of subclinical hypothyroidism with aging [14-16]. However, normal TSH distributions shift toward higher concentrations with age, a consequence leading to overestimation of this diagnosis in the elderly [17]. A longitudinal cohort study looking at elderly patients did not find an association between subclinical hypothyroidism and cardiovascular or all-cause mortality, raising concern for treating mildly supra-normal TSH levels based on currently recommended cut-off limits [18].

Patients with subclinical hypothyroidism represent a dimorphic population, either as pre-runners of overt hypothyroidism with risk factors of thyroid disease or with an indolent form of disease with preserved thyroid function reserve [19]. A prospective study observed that up to $55 \%$ of subclinical hypothyroid patients with TSH levels $>6 \mathrm{mIU} / \mathrm{L}$ eventually progressed to overt hypothyroidism over a 10-year follow-up period [20]. Clinical evidence of goiter and presence of antithyroid antibodies serve as predictive risk-stratifiers in determining progression towards overt hypothyroidism [20, 21].

The clinical importance of subclinical hypothyroidism in cardiovascular disease and mortality remains controversial, with most studies providing conflicting results. This may be explained by the selection of heterogenous patient populations, arbitrarily designated TSH reference limits in defining subclinical hypothyroidism, lack of stratification of study groups based on the degree of TSH elevation, varying study designs and paucity of randomized controlled trials directly addressing patient-outcome relationships.

Despite extensive research, there still exists clinical uncertainty on various aspects surrounding thyroid-related cardiovascular disease. The most recent ACC/AHA guidelines for the diagnosis and management of heart failure recommend measuring thyroid function in all patients with newly diagnosed heart failure, since it represents a potential reversible 
cause of cardiovascular disease. Nonetheless, no specific recommendations have been made with regard to the management of subclinical hypothyroidism in patients with heart failure [2].

Classification systems have been proposed grading subclinical hypothyroidism based on severity assessment into grade 1 (TSH levels $<10 \mathrm{mIU} / \mathrm{L})$ and grade $2(\mathrm{TSH}>10$ $\mathrm{mIU} / \mathrm{L})$ [22]. The natural history may differ significantly between the two groups with grade 2 category patients having higher cardiovascular events and at higher rates of transition to overt hypothyroidism $[23,24]$. A large prospective study involving elderly population ( $>85$ years) noted an association between grade 1 subclinical hyperthyroidism and decreased all-cause mortality [25]. This was later supported by a large retrospective cohort study which also noted lower mortality rates in grade 1 subclinical hypothyroidism patients, suggesting a protective benefit of mildly supra-normal TSH levels [26]. The same study observed an increase in myocardial infarction events in patients with grade 2 subclinical hypothyroidism. Similarly, an international prospective cohort study of 55,287 patients reported increased CHD events and CHDrelated mortality in this subset of patients [20]. Individual participant data analysis did not identify statistically differing CHD outcomes across the age groups [20].

The higher cardiovascular mortality rates in group 2 subclinical hypothyroidism patients are related to known cardiovascular effects of thyroxine on heart function and metabolism. Cardiovascular alterations that occur in overt hypothyroidism have also been identified in subclinical hypothyroidism, effects varying only in the degree of derangement [27]. Of note, mouse model studies have demonstrated serum thyroxine levels not to reflect cardiac tissue T4 levels in mild hypothyroidism, with cardiac tissue hypothyroidism occurring in the presence of normal serum thyroxine levels [28]. Increased systemic vascular resistance, arterial stiffness, and altered endothelial function have been associated with subclinical thyroid dysfunction [27]. Enhanced cardiovascular risk can also be related to altered pro-atherogenic lipid profiles, an effect reversible with institution of levothyroxine replacement therapy [28]. The benefits of levothyroxine treatment on endothelial function and intima-media thickness have been well demonstrated in previous randomized trials [28, 29]. Whether these effects translate into improved patient-cardiovascular clinical outcomes awaits further study.

In the Health Aging and Body Composition populationbased study, the authors investigated the levels of TSH effecting harmful cardiovascular effects by following patients prospectively over 4 years. The study concluded that patients with TSH levels more than $7 \mathrm{mIU} / \mathrm{L}$ and more than $10 \mathrm{mIU} / \mathrm{L}$ had a hazard ratio of 2.58 and 3.26, respectively for developing heart failure [30]. Another study conducted by Rodondi et al in over 55,000 individuals demonstrated a positive correlation between the degree of TSH elevations and cardiovascular event rates and mortality [23]. Collet et al collected data from 10 cohort studies which showed a hazard ratio for CHD-related mortality of 1.24 and 1.21 for CHD events [31]. Several studies suggest that the cutoff of TSH $>10 \mathrm{mIU} / \mathrm{L}$ may be used to define a patient with subclinical hypothyroidism with an increased risk for cardiovascular events. The Cardiovascular Health Study performed echocardiogram routinely for 6 years in a cohort of patients to determine patients at risk for developing heart failure. It was found that patients with a TSH $>10$ $\mathrm{mIU} / \mathrm{L}$ had higher risk of heart failure with low ejection fraction as compared to the population with normal thyroid function [7]. Collet et al also proved that the antibody status of an individual does not render higher risk for CHD since patients with clinical and subclinical hypothyroidism may or may not have positive antibodies [32].

The cardiac-ankle vascular index, an indicator of arteriosclerosis, has been studied in subclinical hypothyroidism and increased index values have been associated with elevated BNP levels, reflecting the effect of decreased tissue T3 in the alteration of the ventricular and arterial wall pressure dynamics [33]. While many studies identify the relation between heart disease and overt hypothyroidism, one study suggested that dilated cardiomyopathy is associated with subclinical hyperthyroidism [34].

It has also been noted that the levels of T3 correlate with the functional level (New York Heart Association (NYHA) class) and that lower hormone levels are associated with higher NYHA classification, making it a predictor of mortality in class III and IV of the NYHA [35]. In patients with heart failure with preserved ejection fraction, a study showed that up to $22 \%$ of these patients had altered thyroid function with low T3 levels [36]. However, available evidence, based on current literature, is still contradicting in certain groups of patients. In a study conducted on patients with heart failure and reduced ejection fraction, neither subclinical hyperthyroidism nor hypothyroidism was found to be significant prognostic factors [37].

\section{Clinical Perspectives}

The association between cardiovascular disease and subclinical hypothyroidism, though significant, is reversible with thyroxine hormone replacement, as reflected by improvement or reversal in some of the components such as diastolic dysfunction and carotid artery intima-media thickness (a marker of subclinical atherosclerosis) [38, 39]. In 2005, a consensus panel from three recognized organizations such as the American Association of Clinical Endocrinologist, the American Thyroid Association, and the Endocrine Society recommended against replacing thyroid hormones if TSH is $<10 \mathrm{mIU} / \mathrm{L}$ but that treatment was reasonable in patient with subclinical hypothyroidism if TSH was $>10 \mathrm{mIU} / \mathrm{L}$ [40]. Current clinical practice guidelines recommend treating subclinical hypothyroid patients with TSH levels with levels greater than $10 \mathrm{mIU} / \mathrm{L}$ $[21,41]$. Thyroxine replacement for TSH levels less than 10 $\mathrm{mIU} / \mathrm{L}$ should be patient-specific and tailored accordingly based on age characteristics and clinical symptoms consistent with hypothyroidism [39]. More studies need to be conducted in order to determine the appropriateness of thyroxine replacement by identifying select high risk subset of subclinical hypothyroid patients, including those likely to progress to overt hypothyroidism. Select patients with heart failure would benefit from thyroid hormone replacement if they are discovered to have subclinical hypothyroidism. This therapeutic benefit is more so in patients with heart failure with preserved ejection 
fraction, a relatively less well studied population.

\section{Conclusion}

To summarize, we may conclude that hypothyroidism and its subclinical counterpart have prognostic implications in patients with heart failure due to its association with increased cardiovascular mortality. Since there exists some evidence of a causal relationship, it may seem appropriate to perform a basic cardiac workup like an echocardiogram to assess for subclinical systolic and diastolic dysfunction as part of initial evaluation. Evidence of cardiac dysfunction may facilitate the determination of appropriateness of thyroxine replacement therapy in subclinical hypothyroidism.

\section{Conflicts of Interest}

We have no conflicts of interest to disclose.

\section{Abbreviations}

TSH: thyroid-stimulating hormone; T3: triiodothyronine; T4: tetraiodothyroxine; SERCA: sarco/endoplasmic reticulum $\mathrm{Ca}^{2+}$-ATPase; ATPase: adenosine 5'-triphosphatase; NYHA: New York Heart Association

\section{References}

1. Gencer B, Collet TH, Virgini V, Bauer DC, Gussekloo J, Cappola AR, Nanchen D, et al. Subclinical thyroid dysfunction and the risk of heart failure events: an individual participant data analysis from 6 prospective cohorts. Circulation. 2012;126(9):1040-1049.

2. Berezin AE, Kremzer AA, Martovitskaya YV, Samura TA, Berezina TA. The Association of Subclinical Hypothyroidism and Pattern of Circulating EndothelialDerived Microparticles Among Chronic Heart Failure Patients. Res Cardiovasc Med. 2015;4(4):e29094.

3. Klein I, Ojamaa K. Thyroid hormone and the cardiovascular system. N Engl J Med. 2001;344(7):501-509.

4. Rohrer DK, Hartong R, Dillmann WH. Influence of thyroid hormone and retinoic acid on slow sarcoplasmic reticulum $\mathrm{Ca} 2+$ ATPase and myosin heavy chain alpha gene expression in cardiac myocytes. Delineation of cis-active DNA elements that confer responsiveness to thyroid hormone but not to retinoic acid. J Biol Chem. 1991;266(13):8638-8646.

5. Brent GA. The molecular basis of thyroid hormone action. N Engl J Med. 1994;331(13):847-853.

6. Kenessey A, Ojamaa K. Thyroid hormone stimulates protein synthesis in the cardiomyocyte by activating the Akt-mTOR and p70S6K pathways. J Biol Chem. 2006;281(30):20666-20672.

7. Biondi B. Mechanisms in endocrinology: Heart failure and thyroid dysfunction. Eur J Endocrinol. 2012;167(5):609618.

8. Selvaraj S, Klein I, Danzi S, Akhter N, Bonow RO, Shah SJ. Association of serum triiodothyronine with B-type natriuretic peptide and severe left ventricular diastolic dysfunction in heart failure with preserved ejection fraction. Am J Cardiol. 2012;110(2):234-239.

9. Ning N, Gao D, Triggiani V, Iacoviello M, Mitchell JE, Ma R, Zhang Y, et al. Prognostic Role of Hypothyroidism in Heart Failure: A Meta-Analysis. Medicine (Baltimore). 2015;94(30):e1159.

10. AlGhalayini K. Prevalence of hypothyroidism in a cohort of Saudi women with heart failure and effect on systolic and diastolic function. J Pak Med Assoc. 2015;65(12):1300-1304.

11. Shuvy M, Shifman OE, Nusair S, Pappo O, Lotan C. Hypothyroidism-induced myocardial damage and heart failure: an overlooked entity. Cardiovasc Pathol. 2009;18(3):183-186.

12. Wang W, Guan H, Gerdes AM, Iervasi G, Yang Y, Tang YD. Thyroid Status, Cardiac Function, and Mortality in Patients With Idiopathic Dilated Cardiomyopathy. J Clin Endocrinol Metab. 2015;100(8):3210-3218.

13. Rodondi N, Newman AB, Vittinghoff E, de Rekeneire N, Satterfield S, Harris TB, Bauer DC. Subclinical hypothyroidism and the risk of heart failure, other cardiovascular events, and death. Arch Intern Med. 2005;165(21):24602466.

14. Hollowell JG, Staehling NW, Flanders WD, Hannon WH, Gunter EW, Spencer CA, Braverman LE. Serum TSH, $\mathrm{T}(4)$, and thyroid antibodies in the United States population (1988 to 1994): National Health and Nutrition Examination Survey (NHANES III). J Clin Endocrinol Metab. 2002;87(2):489-499.

15. Tunbridge WM, Evered DC, Hall R, Appleton D, Brewis M, Clark F, Evans JG, et al. The spectrum of thyroid disease in a community: the Whickham survey. Clin Endocrinol (Oxf). 1977;7(6):481-493.

16. Sawin CT, Chopra D, Azizi F, Mannix JE, Bacharach $\mathrm{P}$. The aging thyroid. Increased prevalence of elevated serum thyrotropin levels in the elderly. JAMA. 1979;242(3):247-250.

17. Surks MI, Hollowell JG. Age-specific distribution of serum thyrotropin and antithyroid antibodies in the US population: implications for the prevalence of subclinical hypothyroidism. J Clin Endocrinol Metab. 2007;92(12):4575-4582.

18. Waring AC, Arnold AM, Newman AB, Buzkova P, Hirsch C, Cappola AR. Longitudinal changes in thyroid function in the oldest old and survival: the cardiovascular health study all-stars study. J Clin Endocrinol Metab. 2012;97(11):3944-3950.

19. Kabadi UM. 'Subclinical hypothyroidism'. Natural course of the syndrome during a prolonged follow-up study. Arch Intern Med. 1993;153(8):957-961.

20. Huber G, Staub JJ, Meier C, Mitrache C, Guglielmetti M, Huber P, Braverman LE. Prospective study of the spontaneous course of subclinical hypothyroidism: prognostic value of thyrotropin, thyroid reserve, and thyroid antibod- 
ies. J Clin Endocrinol Metab. 2002;87(7):3221-3226.

21. Pearce SH, Brabant G, Duntas LH, Monzani F, Peeters RP, Razvi S, Wemeau JL. 2013 ETA Guideline: Management of Subclinical Hypothyroidism. Eur Thyroid J. 2013;2(4):215-228.

22. Surks MI, Ortiz E, Daniels GH, Sawin CT, Col NF, Cobin RH, Franklyn JA, et al. Subclinical thyroid disease: scientific review and guidelines for diagnosis and management. JAMA. 2004;291(2):228-238.

23. Rodondi N, den Elzen WP, Bauer DC, Cappola AR, Razvi S, Walsh JP, Asvold BO, et al. Subclinical hypothyroidism and the risk of coronary heart disease and mortality. JAMA. 2010;304(12):1365-1374.

24. Somwaru LL, Rariy CM, Arnold AM, Cappola AR. The natural history of subclinical hypothyroidism in the elderly: the cardiovascular health study. J Clin Endocrinol Metab. 2012;97(6):1962-1969.

25. Gussekloo J, van Exel E, de Craen AJ, Meinders AE, Frolich M, Westendorp RG. Thyroid status, disability and cognitive function, and survival in old age. JAMA. 2004;292(21):2591-2599.

26. Selmer C, Olesen JB, Hansen ML, von Kappelgaard LM, Madsen JC, Hansen PR, Pedersen OD, et al. Subclinical and overt thyroid dysfunction and risk of all-cause mortality and cardiovascular events: a large population study. J Clin Endocrinol Metab. 2014;99(7):2372-2382.

27. Biondi B, Cooper DS. The clinical significance of subclinical thyroid dysfunction. Endocr Rev. 2008;29(1):76131.

28. Monzani F, Caraccio N, Kozakowa M, Dardano A, Vittone F, Virdis A, Taddei S, et al. Effect of levothyroxine replacement on lipid profile and intima-media thickness in subclinical hypothyroidism: a double-blind, placebo- controlled study. J Clin Endocrinol Metab. 2004;89(5):2099-2106.

29. Razvi S, Ingoe L, Keeka G, Oates C, McMillan C, Weaver JU. The beneficial effect of L-thyroxine on cardiovascular risk factors, endothelial function, and quality of life in subclinical hypothyroidism: randomized, crossover trial. J Clin Endocrinol Metab. 2007;92(5):1715-1723.

30. Rugge B, Balshem H, Sehgal R, et al. Screening and Treatment of Subclinical Hypothyroidism or Hyperthyroidism. Agency for Healthcare Research and Quality (US. Comparative Effectiveness Reviews). 2011 Oct, No. 24. Report No.: 11(12)-EHC033-EF.

31. Collet TH, Gussekloo J, Bauer DC, den Elzen WP, Cap- pola AR, Balmer P, Iervasi G, et al. Subclinical hyperthyroidism and the risk of coronary heart disease and mortality. Arch Intern Med. 2012;172(10):799-809.

32. Collet TH, Bauer DC, Cappola AR, Asvold BO, Weiler S, Vittinghoff E, Gussekloo J, et al. Thyroid antibody status, subclinical hypothyroidism, and the risk of coronary heart disease: an individual participant data analysis. J Clin Endocrinol Metab. 2014;99(9):3353-3362.

33. Masaki M, Komamura K, Goda A, Hirotani S, Otsuka M, Nakabo A, Fukui M, et al. Elevated arterial stiffness and diastolic dysfunction in subclinical hypothyroidism. Circ J. 2014;78(6):1494-1500.

34. Li X, Yang X, Wang Y, Ding L, Wang J, Hua W. The prevalence and prognostic effects of subclinical thyroid dysfunction in dilated cardiomyopathy patients: a singlecenter cohort study. J Card Fail. 2014;20(7):506-512.

35. Danzi S, Klein I. Thyroid hormone and the cardiovascular system. Minerva Endocrinol. 2004;29(3):139-150.

36. Kinugasa Y, Yamamoto K. Subclinical hypothyroidism as a new therapeutic target for patients with heart failure with preserved ejection fraction. Circ J. 2014;78(6):13331334.

37. Frey A, Kroiss M, Berliner D, Seifert M, Allolio B, Guder G, Ertl G, et al. Prognostic impact of subclinical thyroid dysfunction in heart failure. Int $\mathrm{J}$ Cardiol. 2013;168(1):300-305.

38. Biondi B, Fazio S, Palmieri EA, Carella C, Panza N, Cittadini A, Bone F, et al. Left ventricular diastolic dysfunction in patients with subclinical hypothyroidism. J Clin Endocrinol Metab. 1999;84(6):2064-2067.

39. Rhee SS, Pearce EN. Update: Systemic Diseases and the Cardiovascular System (II). The endocrine system and the heart: a review. Rev Esp Cardiol. 2011;64(3):220231.

40. Gharib H, Tuttle RM, Baskin HJ, Fish LH, Singer PA, McDermott MT. Subclinical thyroid dysfunction: a joint statement on management from the American Association of Clinical Endocrinologists, the American Thyroid Association, and the Endocrine Society. J Clin Endocrinol Metab. 2005;90(1):581-585; discussion 586-587.

41. Garber JR, Cobin RH, Gharib H, Hennessey JV, Klein I, Mechanick JI, Pessah-Pollack R, et al. Clinical practice guidelines for hypothyroidism in adults: cosponsored by the American Association of Clinical Endocrinologists and the American Thyroid Association. Endocr Pract. 2012;18(6):988-1028. 